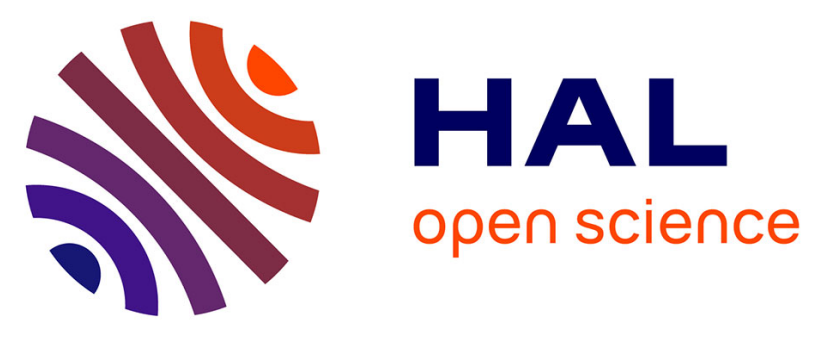

\title{
Synthesis, antibacterial evaluation, Raman, crystal structure and Hirshfeld surface analysis of a new 3-(4-fluorophenyl)-6-methyl-2-(propylthio)quinazolin- $4(3 \mathrm{H})$-one
}

Mohammed Geesi, Yassine Riadi, Abdellah Kaiba, El Hassane Anouar, Oussama Ouerghi, Elmutasim O. Ibnouf, Philippe Guionneau

\section{To cite this version:}

Mohammed Geesi, Yassine Riadi, Abdellah Kaiba, El Hassane Anouar, Oussama Ouerghi, et al.. Synthesis, antibacterial evaluation, Raman, crystal structure and Hirshfeld surface analysis of a new 3(4-fluorophenyl)-6-methyl-2-(propylthio)quinazolin-4(3H)-one. Journal of Molecular Structure, 2020, 1215,128265 (7 p.). 10.1016/j.molstruc.2020.128265 . hal-02613514

\section{HAL Id: hal-02613514 https://hal.science/hal-02613514}

Submitted on 26 May 2021

HAL is a multi-disciplinary open access archive for the deposit and dissemination of scientific research documents, whether they are published or not. The documents may come from teaching and research institutions in France or abroad, or from public or private research centers.
L'archive ouverte pluridisciplinaire HAL, est destinée au dépôt et à la diffusion de documents scientifiques de niveau recherche, publiés ou non, émanant des établissements d'enseignement et de recherche français ou étrangers, des laboratoires publics ou privés. 


\title{
Synthesis, antibacterial evaluation, Raman, Crystal Structure and Hirshfeld Surface analysis of a new 3-(4-fluorophenyl)-6-methyl-2- (propylthio)quinazolin-4(3H)-one
}

\author{
Mohammed H. Geesi ${ }^{\mathrm{a}}$, Yassine Riadi ${ }^{\mathrm{b}}$, Abdellah Kaiba ${ }^{\mathrm{c}}$, El Hassane Anouar ${ }^{\mathrm{a}}$, Oussama Ouerghi ${ }^{\mathrm{cd}}$ \\ Elmutasim O. Ibnouf ${ }^{\text {ef }}$, Philipe Guionneau ${ }^{\mathrm{g}}$ \\ a Department of Chemistry, College of Science and Humanities in Al-Kharj, Prince Sattam Bin Abdulaziz University, Al-Kharj, 11942, \\ Saudi Arabia \\ ${ }^{\mathrm{b}}$ Department of Pharmaceutical Chemistry, College of Pharmacy, Prince Sattam Bin Abdulaziz University, Al-Kharj, 11942, Saudi \\ Arabia \\ ${ }^{c}$ Department of Physic, College of Science and Humanities in Al-Kharj, Prince Sattam Bin Abdulaziz University, Al-Kharj, 11942, \\ Saudi Arabia \\ ${ }^{\mathrm{d}}$ Université Tunis El Manar, Tunis, 1068, Tunisia \\ ${ }^{\mathrm{e}}$ Department of Pharmaceutics, College of Pharmacy, Prince Sattam Bin Abdulaziz University, Al-Kharj, 11942, Saudi Arabia \\ ${ }^{\mathrm{f}}$ Department of Medical Microbiology, Faculty of Medical Laboratory Sciences, Omdurman Islamic University, Sudan \\ ${ }^{g}$ CNRS, Univ. Bordeaux, ICMCB, UPR 9048, 87, Avenue Du Docteur Schweitzer, F-33600, Pessac, France
}

Corresponding author : Yassine Riadi, Department of Pharmaceutical Chemistry, College of Pharmacy, Prince Sattam Bin Abdulaziz University, Al-Kharj, 11942, Saudi Arabia.y.riadi@psau.edu.sa / yassinriadi@yahoo.fr

\begin{abstract}
An efficient route was reported for synthesis of a novel 3-(4-fluorophenyl)-6-methyl-2(propylthio)quinazolin-4(3H)-one. The synthesized compound was prepared by a sulphur arylation reaction and was tested against some bacterial strains. Raman analysis was conducted on the synthesized derivative, which had the following properties: empirical formula $\left(\mathrm{C}_{18} \mathrm{H}_{17} \mathrm{Cl} \mathrm{N}_{2} \mathrm{O}\right.$ ), system (monoclinic), space group $\left(\mathrm{P} 2_{1} / \mathrm{c}\right)$, unit parameters cell $(\boldsymbol{a}=12.7137(7) \AA, \boldsymbol{b}=7.5018(4) \AA, \boldsymbol{c}=17.1209(9) \AA$ and $\left.\beta=11.0042(15)^{\circ}\right)$, volume $\left(V=1524.42 \AA^{3}\right), Z=4$, temperature $(150(2) K)$. The single crystal structure was resolved and refined to $(\boldsymbol{R}=0.0374, \mathrm{w} R=0.1040)$. The non-hydrogen atoms were refined anisotropically and the hydrogen atoms were placed theoretically. The Hirshfeld surface and fingerprint plots were obtained. The electrostatic potential surface (ESP) was also derived using the density functional theory method.
\end{abstract}

Keywords : 3-(4-Fluorophenyl)-6-methyl-2-(propylthio)quinazolin-4(3H)-one ; Antibacterial ; Crystal structure ; Hirshfeld surface analysis ; Electrostatic potential surface. 


\section{Introduction}

Heterocyclic derivatives have attracted considerable interest in last years for their versatile properties in chemistry, biology, pharmacy and medicine. The manipulation of their structures opens the way to the discovery of several drugs. It is well known that more than $90 \%$ of new drugs are made up of heterocyclics, which play a vital role as an interface between chemistry and biology [1-10].

Heterocyclic nitrogenous and oxygenated systems are considered to be an important line of research, thus having a particular interest, because of their remarkable properties.

Among these heterocyclic are quinazolines which are nitrogen heterocycles found abundantly in organic molecules. They are present in many natural substances, and in a multitude of biologically active compounds. They are of considerable importance in the pharmaceutical field and, in fact, are found in many of the bioactive structures patented in recent years. Quinazoline derivatives are very attractive molecules for researchers due to their diverse applications, despite of that their synthesis often either requires several stages or the use of functionalised starting materials. The development of reactions that would allow the rapid and efficient synthesis of polyfunctionalised quinazolines has always been a substantial challenge for organic chemists [1,2].

Quinazolines have shown antibacterial and anti-inflammatory properties [3], as well as analgesic [4], anti-cancer [5], anti-tuberculosis [6], anticonvulsant [7], antioxidant [8], antihypertension [9] and anti-diabetes activities [10].

For these reasons, and based on our recent research aimed at developing a new strategy to access to heterocyclic agents [11-17]. Herein, we reported the synthesis of new quinazolinone derivative 3-(4-fluorophenyl)-6-methyl2(propylthio)quinazolin-4(3H)-one (5) with good yield (Scheme 1) and its antibacterial activity was tested.

In addition, Raman and crystallographic study of the prepared quinazolinone derivative were conducted at room temperature, along with description of its Hirshfeld surface, fingerprint plots and electrostatic potential surface (ESP).

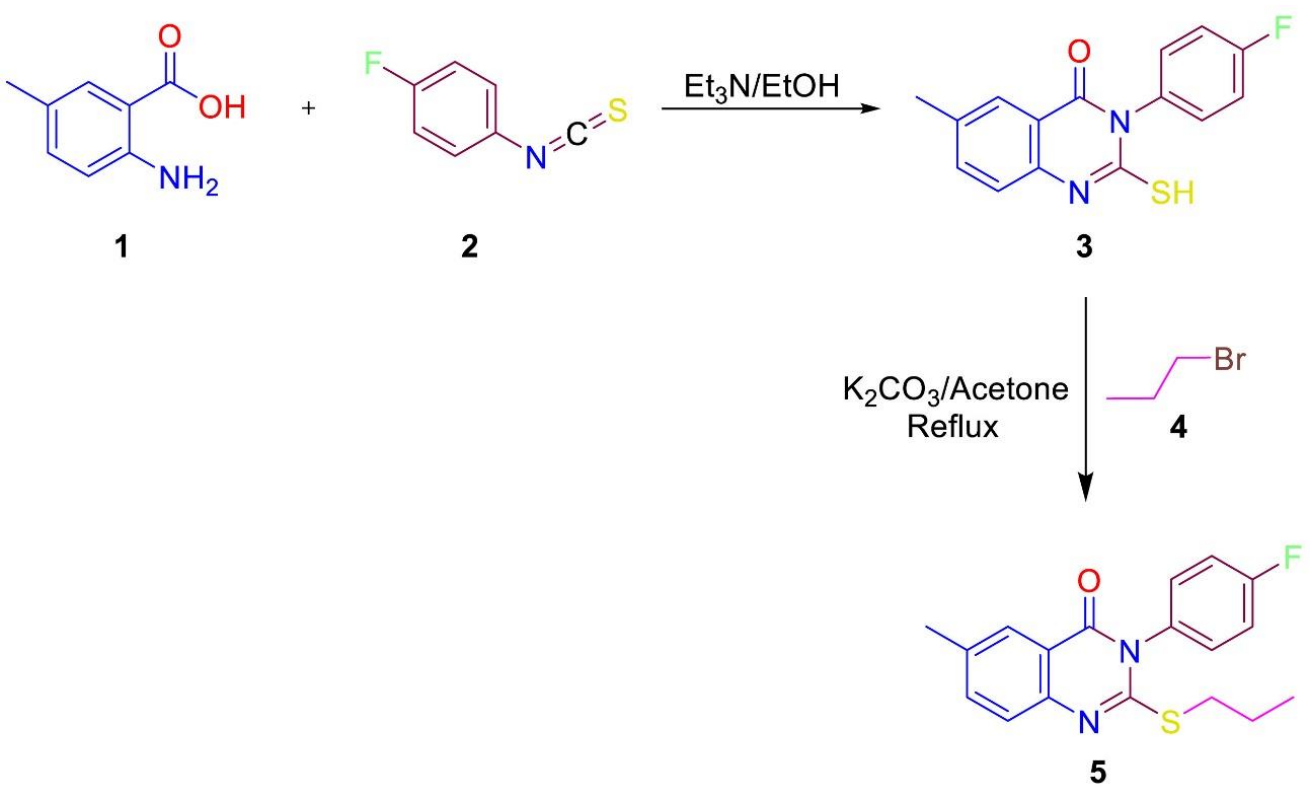

Scheme 1. Strategy of the synthesis of 3-(4-fluorophenyl)-6-methyl-2(propylthio)quinazolin-4(3H)-one (5). 


\section{Synthesis}

We used the same strategy we described in our previous work [18]. First, 4-fluorophenylisothiocyanate (1 mmol) was added dropwise under stirring to a mixture of 5-methylanthranilic acid (1 mmol) in absolute ethanol $(20 \mathrm{~mL})$, followed by addition of triethylamine $(1.1 \mathrm{mmol}, 0.11 \mathrm{~g})$. This mixture was refluxed for $1.5 \mathrm{~h}$ to ensure total consumption of the starting reactants (as determined by thin layer chromatography [TLC]). The mixture was filtered and the solvent was removed in vacuo. The resulting crude solid was recrystallised from ethanol to achieve the pure product. As a second step, intermediate $\mathbf{3}(1 \mathrm{mmol})$ was reacted with 1-propylbromide $(1 \mathrm{mmol})$ in acetone $(10 \mathrm{~mL})$ containing anhydrous potassium acetate $(1.5 \mathrm{mmol})$ under stirring for $10 \mathrm{~h}$. After completion of the reaction, the mixture was filtered and the solvent removed in vacuo. The resulting solid was recrystallised from ethanol to give the title compound 3-(4-fluorophenyl)-6-methyl-2-(propylthio)quinazolin-4(3H)-one as a white crystal (yield 74\%).

\section{Antibacterial activity}

Derivative 5 was assessed for the antibacterial activity against 2 g-negative bacteria, (Escherichia coli and Pseudomonas aeruginosa) and 2 g-positive bacteria (methicillin resistant Staphylococcus aureus [MRSA] and Bacillus subtilis) per the standard method [19].

Dimethylsulphoxide (DMSO) was used as the negative control and the antibiotic ciprofloxacin was used as the positive control. The minimum inhibitory concentration (MIC) as determined by preparing the derivative $\mathbf{5}$ at concentrations of $12.5,18.75,25,38.5,50,75$ and $100 \mu \mathrm{g} / \mathrm{mL}$ in DMSO, and serially diluted test samples of the derivative (in $200 \mu \mathrm{L}$ ) were added to 96-well microtrays. The test microorganism was added to the microtray wells to give a final volume of $400 \mu \mathrm{L}$, and the plates were incubated at $37^{\circ} \mathrm{C}$ for $24 \mathrm{~h}$. The MIC value was defined as the lowest concentration of a compound that inhibited the visible growth of bacteria. Each assay was performed in duplicate.

The activity against the targeted bacterial strains is shown in Table 1. The derivative 5 was active against two bacteria.

Table 1

The antibacterial activity of the quinazoline $\mathbf{5}{ }^{\text {a }}$

\begin{tabular}{|c|c|c|c|c|c|}
\hline & & \multicolumn{4}{|c|}{ Bacterial Strains } \\
\hline & & $\mathrm{Ec}$ & $\mathrm{Pa}$ & Bs & MRSA \\
\hline \multirow[t]{3}{*}{ Quinazoline derivative } & Inhibition zone in $\mathrm{mm}(100 \mu \mathrm{g} / \mathrm{ml})$ & 23 & - & - & 18 \\
\hline & $\operatorname{MIC}(\mu \mathrm{g} / \mathrm{ml})$ & 18.75 & b & b & 38.5 \\
\hline & $\mathrm{MBC}(\mu \mathrm{g} / \mathrm{ml})$ & 12.5 & b & b & 25 \\
\hline Ciprofloxacin & $\operatorname{MIC}(\mu \mathrm{g} / \mathrm{ml})$ & 12.5 & 12.5 & 12.5 & 18.75 \\
\hline
\end{tabular}

${ }^{a}$ MIC: Minimum inhibitory concentration in $\mu \mathrm{g} / \mathrm{mL}$. MBC: Minimum bactericidal concentration.

${ }^{\mathrm{b}}$ No activity, no zone of inhibition.

\section{Raman spectroscopy}

The different steps of the reaction were further monitored by Raman spectroscopy. The corresponding spectra are depicted in Fig. 1. Qualitatively, the profile of the Raman spectrum for the final product differed significantly from the spectra of the initial and the intermediate products. Indeed, because of their aromatic ring vibrations, quinazolines are recognised to absorb strongly in the range $1650-1300 \mathrm{~cm}^{-1}$, and they typically display six bands of variable intensity $[20,21]$. In the region of less than $1000 \mathrm{~cm}^{-1}$, bands associated with the C-H out-of-plane deformation vibrations are observed. This could be ascribed to the additional substituent in the final product and would explain the difference in its spectral profile in this region with respect to both the initial and intermediate products. 


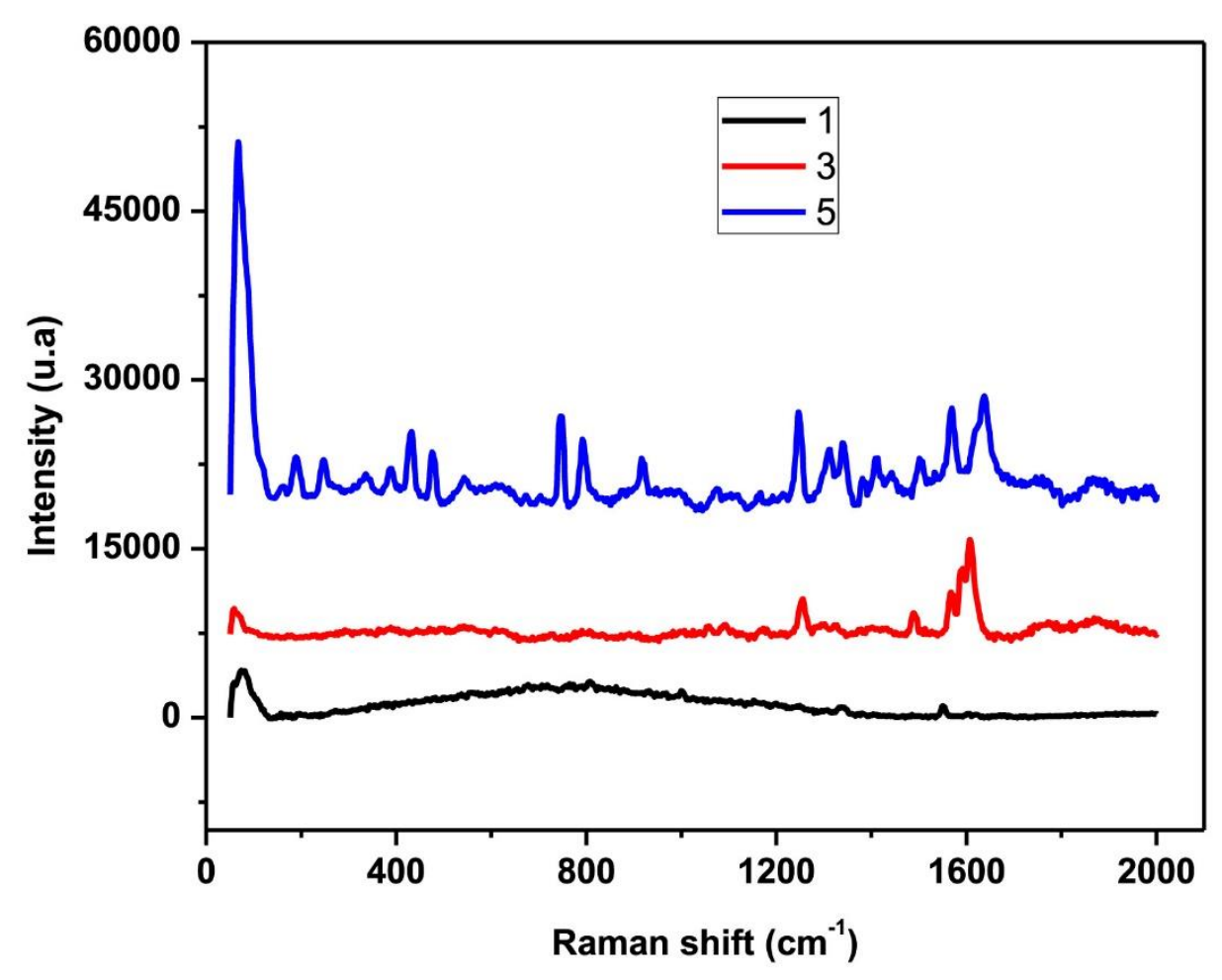

Fig. 1. Raman spectrum of the derivatives 1,3 and 5 .

\section{Crystallographic characterisation}

A single crystal was selected for X-ray diffraction measurement. A Nonius_Kappa_CCD diffractometer with a molybdenum anticathode was used to make the full data collection. The $\boldsymbol{\phi}$ and $\boldsymbol{\omega}$ scan modes were used, and the completeness was about $99.9 \%$. The DENZO-SMN program was used to reduce the data. The structure was solved using SIR97 [22] and the refinement of atomic parameters based on a full-matrix least squares technique $F^{2}$ using SHELX97 [23]. The non-hydrogen atoms were refined anisotropically, and the hydrogen atoms were placed theoretically. All these programs were used within the WINGX package [24]. Low difference electron densities were detected between 0.324 and $-0.232 \mathrm{e} / \AA^{-3}$.

The crystallographic data and experimental parameters for the intensity collection are summarised in Table 2. For the structural data from the Cambridge Crystallographic Data Centre (CCDC), see supplementary publication No CCDC1979924. These data are also freely accessible from the following link: www.ccdc.cam.ac.uk/data_request/cif. The asymmetric unit of the title crystal structure is presented in Fig. 2.

Table 2

Crystallographic and structure refinement data.

\begin{tabular}{ll}
\hline Crystal & Colorless \\
Crystal size & $0.16 \times 0.08 \times 0.08 \mathrm{~mm}^{3}$ \\
Wavelength & Mo K $\alpha$ radiation $(0.71069 \AA)$ \\
Absorption coefficient & $0.254 \mathrm{~mm}^{-1}$ \\
Theta range for data collection & $1.72-28.36^{\circ}$. \\
Reflections collected & 26041 \\
Independent reflections & $3798[R($ int $)=0.0492]$ \\
Completeness to theta $=28.36^{\circ}$ & $99.9 \%$ \\
Refinement method & Full-matrix least-squares on $\mathrm{F}^{2}$ \\
Goodness-of-fit on $F^{2}$ & 1.036 \\
Final R indices $[I>2 \operatorname{sigma}(I)]$ & $R_{1}=0.037$, WR $R_{2}=0.1040$ \\
Programs & SIR97 [22]' SHELEX 97 [23] \\
\hline
\end{tabular}




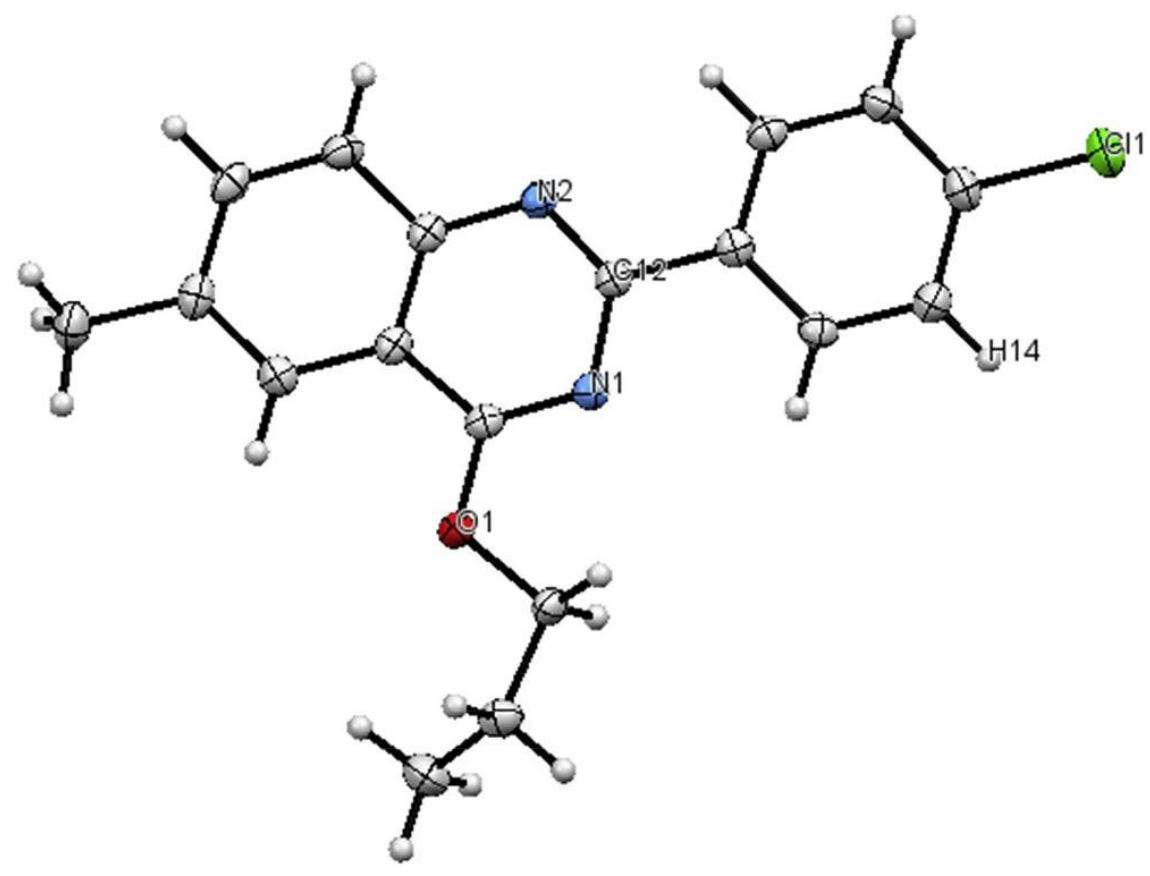

Fig. 2. Asymmetric unit cell of the compound 5.

In the crystal, the hydrogen bonds and $\pi-\pi$ stacking interactions assure the connection between molecules. The hydrogen bond involves $\mathrm{C}-\mathrm{H} \cdots \mathrm{N}$, where the $\mathrm{C}-\mathrm{H} \cdots \mathrm{N}$ distance is $2.614 \AA$. Slight $\pi-\pi$ stacking interactions also occur between the rings of the molecule (3.326 $\AA$ and $3.329 \AA$ ) (Fig. 3). The $\mathrm{C}-\mathrm{C}$ distances fall in the range 1.381(7)-1.505(6) $\AA$. The C-N distance is between 1.311(5) $\AA$ and 1.379(5) $\AA$. The $\mathrm{C}-\mathrm{Cl}$ distance is about $1.742(5) \AA$. The distance between carbon and oxygen is $1.343(5) \AA$ and 1.453(4) $\AA$ (Fig. 4). The torsion angle $\mathrm{CH}_{3}-\mathrm{CH}_{2}-\mathrm{CH}_{2}-\mathrm{O}$ is $61.64^{\circ}$ and the $\mathrm{Cl}-\mathrm{C}_{6} \mathrm{H}_{4}$ forms an angle of $13.53^{\circ}$ with the molecular plane (Fig. 5).

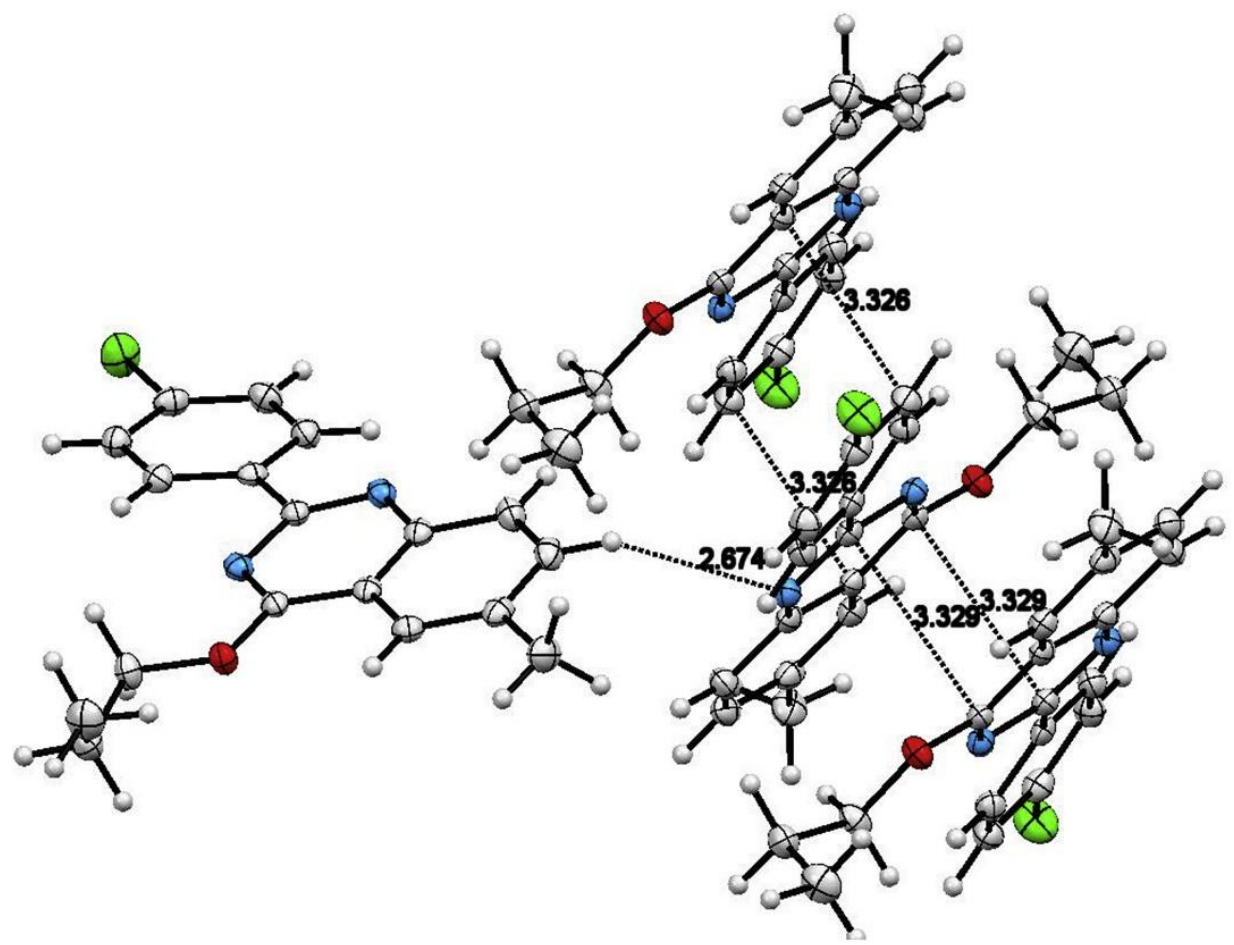

Fig. 3. View showing the connection between the molecules by $C-H \cdots N$ hydrogen bonds and $\pi-\pi$ stacking interactions (dashed lines). 


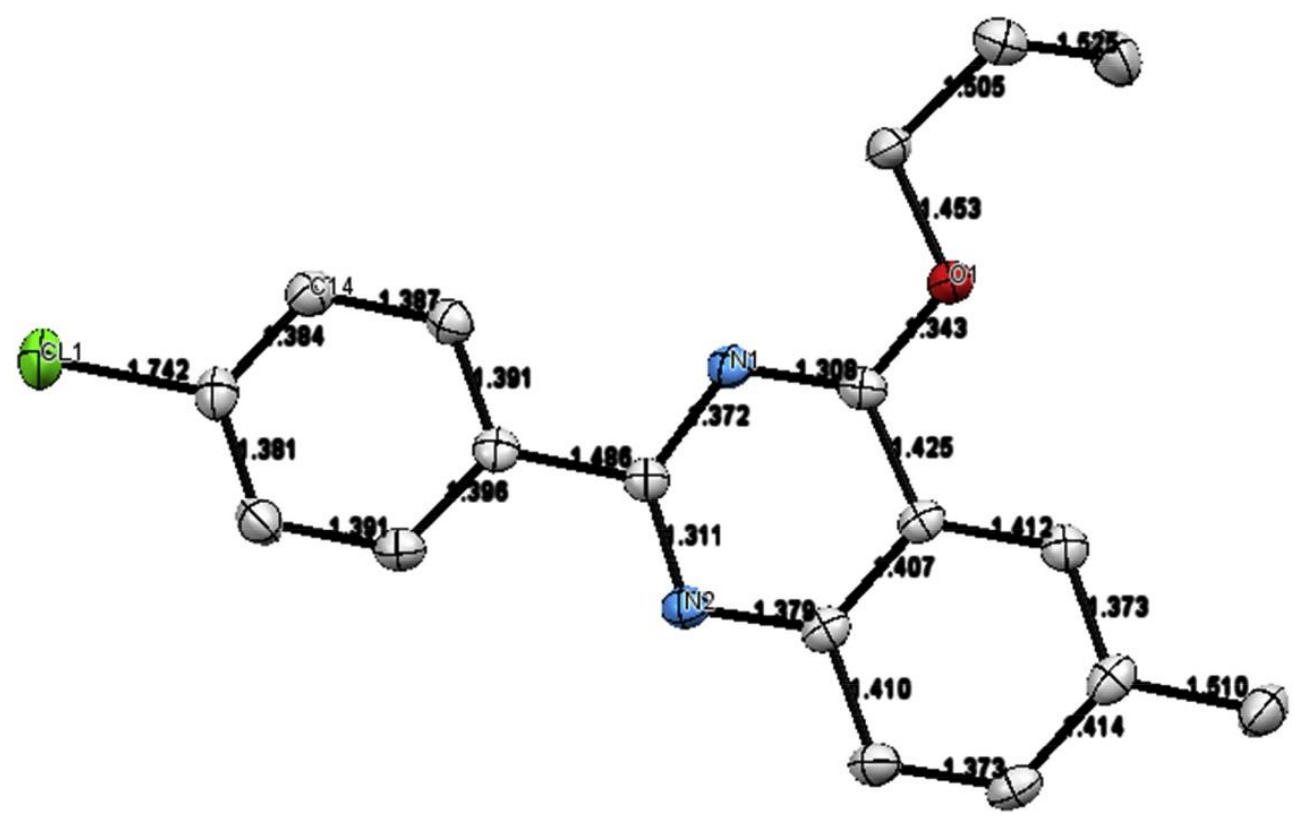

Fig. 4. View showing all the bonds length distances between atoms ( $\AA$ unit) in asymmetric unit cell. Hydrogen atoms are omit for clarity.

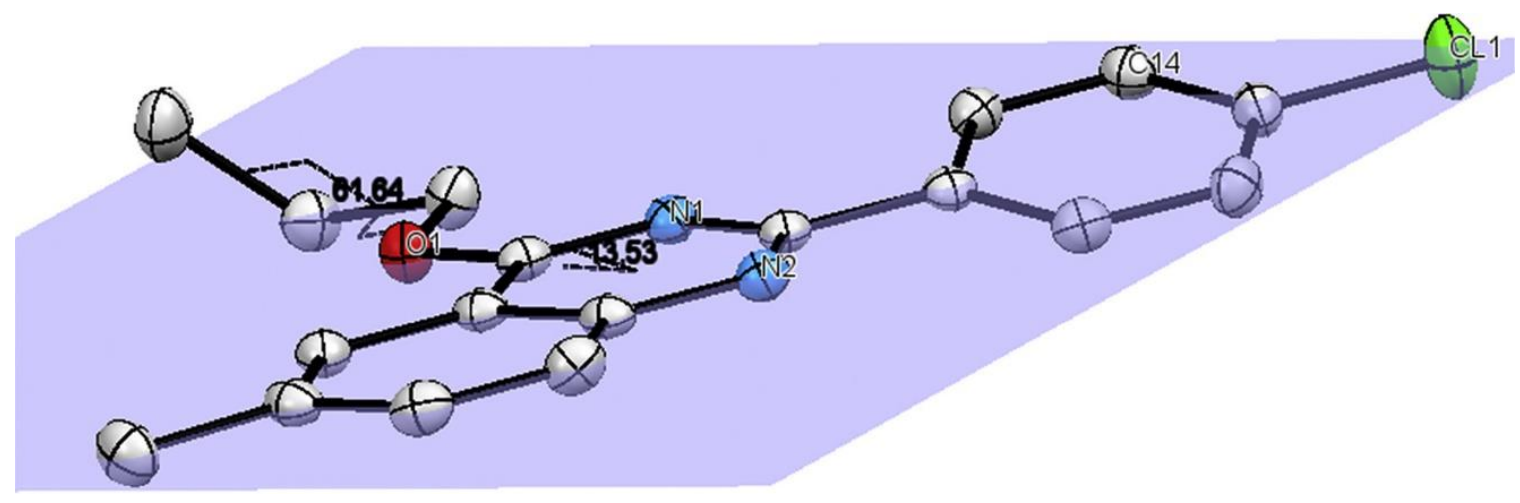

Fig. 5. View showing the torsion angle $\left(\mathrm{CH}_{3}-\left(\mathrm{CH}_{2}\right)_{2}-\mathrm{O}\right)$ and angle between $\mathrm{Cl}-\mathrm{C}_{6} \mathrm{H}_{4}$ - and molecule plan. Hydrogen atoms are omit for clarity.

\section{Computational details}

\subsection{Hirshfeld surface calculations}

The Hirshfeld surface and fingerprint plots of the synthesized compound were obtained using the Crystal Explorer 3.0 package [25]. The dnorm plots were mapped with a colour scale range of -0.0432 au (blue) and 1.084 au (red). The red spots on the Hirshfeld surface indicate the closest interactions between the atoms named in the compound units. The 2D fingerprint plots were displayed using the expanded $0.6-2.8 \AA$. The electrostatic potential surface (ESP) of the title compound was calculated using density functional theory (DFT) methods at the B3LYP/6-311+G(d,p) level of theory using the Gaussian 09 package [26].

\subsection{Hirshfeld surface analysis}

The Hirshfeld surfaces mapped over $\mathrm{d}_{\text {norm}}$, shape index and curvedness for the title compound were obtained using Crystal Explorer 3.0 (Fig. 6). The internal and external ( $d_{i}$ and $d_{e}$ ) contact distances from the Hirshfeld surface to the nearest atom inside and outside enable the analysis of the intermolecular interactions through the mapping of $\mathrm{d}_{\text {norm. }}$. 


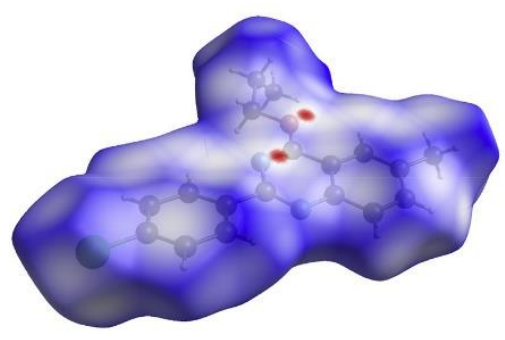

(a)

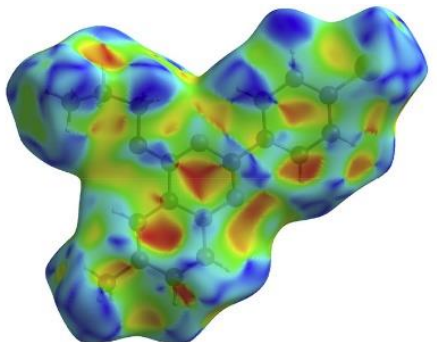

(b)

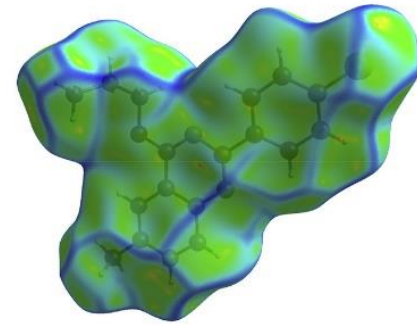

(c)

Fig. 6. Hirshfeld surface mapped over $(a) d_{n o r m},(b)$ shape-index and $(c)$ curvedness.

The red spots on the Hirshfeld surface of the compound $\mathbf{5}$ indicate the existence of intermolecular interactions (intercontacts) in the crystalline environment of the title compound (Fig. 7, left). The Hirshfeld surface over $\mathrm{d}_{\text {norm }}$ shows that the intermolecular interactions between the name of the compound are pi-stacking interactions, and the units are stacked in a head-to-tail arrangement, one above the other. The intermolecular distance between the stacked units is of 3.31 A (Fig. 7).
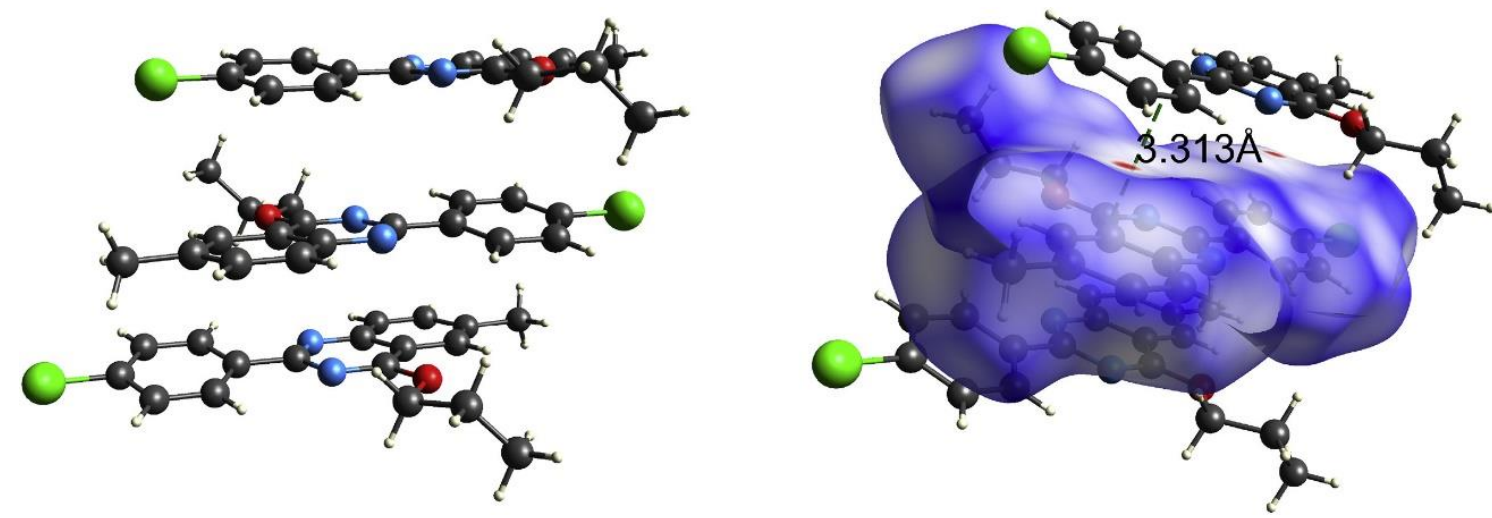

Fig. 7. $d_{\text {norm }}$ mapped on the Hirshfeld surface for visualizing the intermolecular interactions of compound 5.

The electrostatic potentials were calculated using DFT at the B3LYP/6-31+G(d,p) level of theory (Fig. 8). The negative region of the electrostatic potential appears in red and corresponds to hydrogen bond acceptors, while the positive region of the electrostatic potential appears in blue and corresponds to hydrogen-bond donors. The $\mathrm{N} 1$ atom of the quinazoline ring clearly corresponds to a hydrogen atom acceptor (Fig. 8).

The two-dimensional fingerprint plots for most of the intercontacts of the title compound are shown in Fig. 9 and summarised in Table 3. The highest interatomic contact contributions were found between hydrogen atoms $\mathrm{H} \cdots \mathrm{H}$, at $49.1 \%$ (Fig. 9), followed by $\mathrm{C} \cdots \mathrm{H} / \mathrm{H} \cdots \mathrm{C}$ and $\mathrm{Cl} \cdots \mathrm{H} / \mathrm{H} \cdots \mathrm{Cl}$, with contributions of $49.6,18.8$, and $15.5 \%$, respectively. 


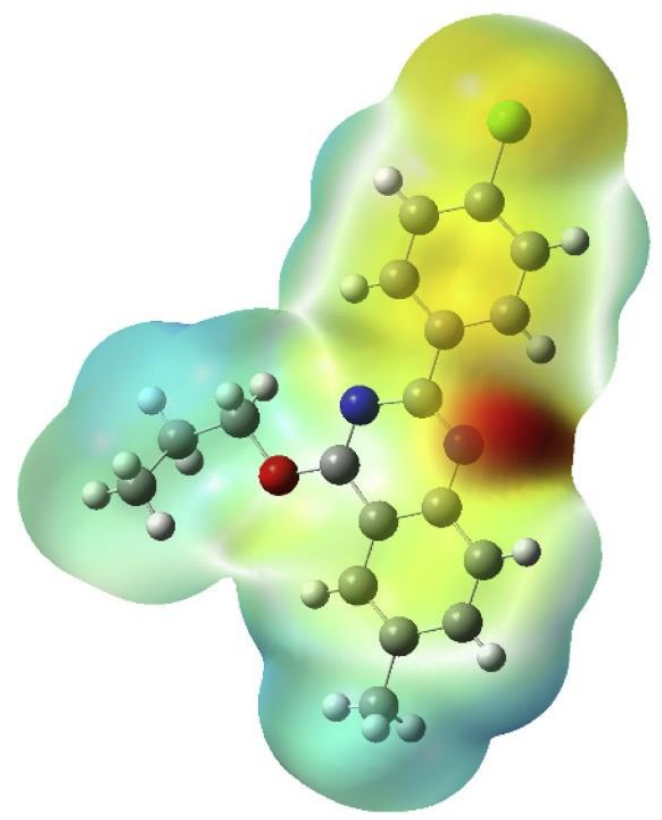

Fig. 8. EPS of the tilted compound obtained at the B3LYP/6-311+G(d,p) level.

Table 3

Summary of the most closest contacts and their percentage contributions to the Hirshfeld surface.

\begin{tabular}{ll}
\hline Type of contact & Contribution (\%) \\
\hline $\mathrm{H} \cdots \mathrm{H}$ & 49.60 \\
$\mathrm{C} \cdots \mathrm{H} / \mathrm{H} \cdots \mathrm{C}$ & 18.80 \\
$\mathrm{Cl} \cdots \mathrm{H} / \mathrm{H} \cdots \mathrm{Cl}$ & 15.00 \\
$\mathrm{C} \cdots \mathrm{C} / \mathrm{C} \cdots \mathrm{C}$ & 5.30 \\
$\mathrm{~N} \cdots \mathrm{H} / \mathrm{H} \cdots \mathrm{N}$ & 4.30 \\
$\mathrm{~N} \cdots \mathrm{C} / \mathrm{C} \cdots \mathrm{N}$ & 3.10 \\
\hline
\end{tabular}



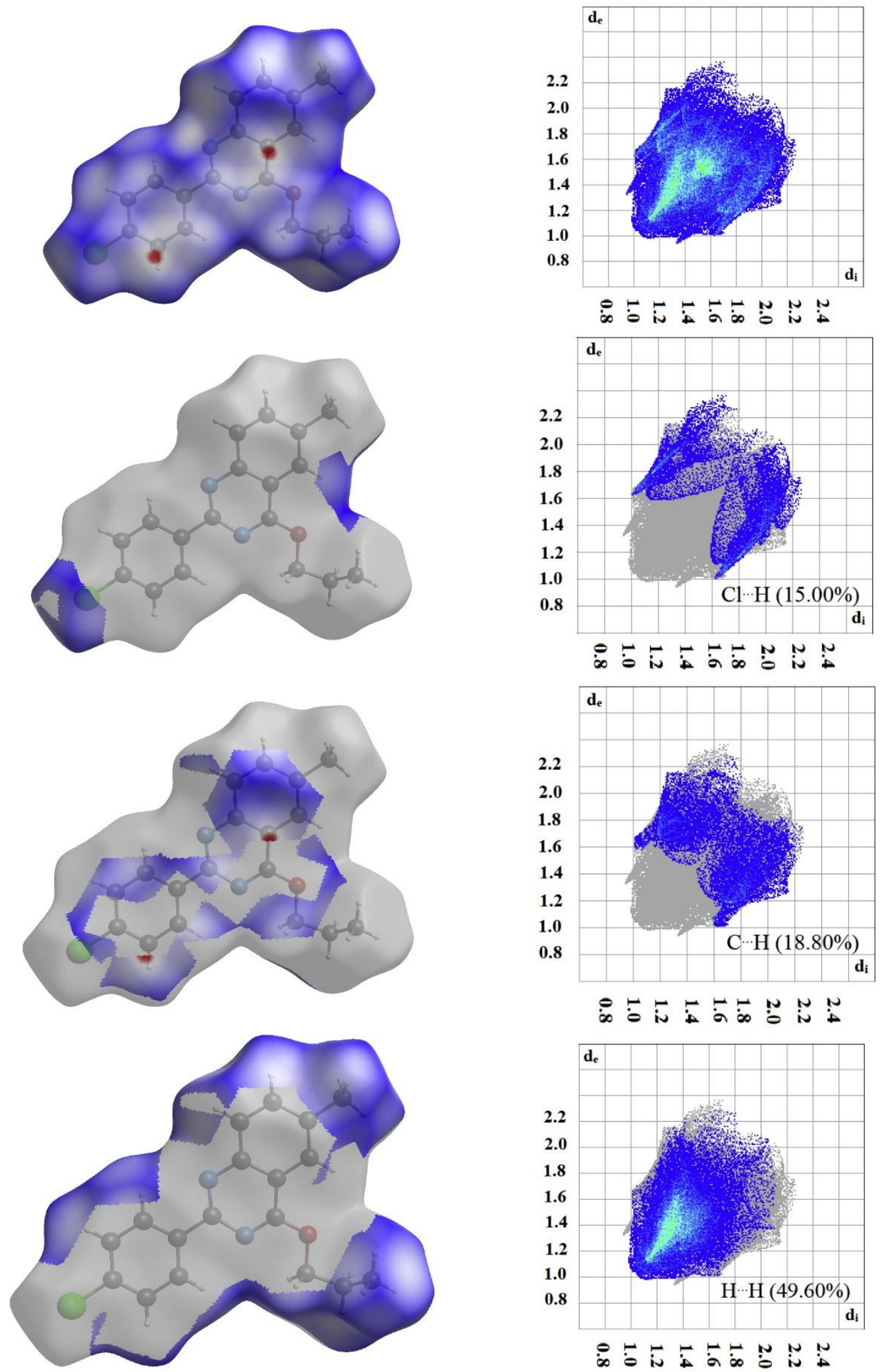

Fig. 9. The two-dimensional fingerprint plots for the title compound showing the most intercontacts. 


\section{Conclusion}

Herein, we have reported the synthesis of a novel 3-(4-fluorophenyl)-6-methyl-2-(propylthio)quinazolin-4(3H)one (5), and its antibacterial activity has assessed against four bacterial strains. The structure of the 3-(4fluorophenyl)-6-methyl-2-(propylthio)quinazolin-4(3H)-one was determined by single crystal XRD studies. The compound crystallized in monoclinic crystal system with $\mathrm{P} 21 / \mathrm{c}$ space group. It exhibited hydrogen bond interaction $\mathrm{C}-\mathrm{H} \cdots \mathrm{N}$ Slight $\pi-\pi$ stacking interactions between rings of the molecule that assure the connection between molecules and stabilizes the crystal. Raman analysis of synthesized compound was investigated. Moreover, the contribution of these interactions was also analysed by visualizing Hirshfeld surface. In addition, the electrostatic potential surface (ESP) was obtained using the DFT method and the radical $\mathrm{CH}_{3}-\mathrm{CH}_{2}-\mathrm{CH}_{2}-\mathrm{O}-$ of the molecule is totally twisted and there is slight twisting at the molecule plane level.

CRediT authorship contribution statement : Mohammed H. Geesi: Conceptualization, Methodology, Software, Validation, Formal analysis, Investigation, Resources, Data curation, Writing - original draft, Writing - review \& editing, Visualization, Supervision, Project administration, Funding acquisition. Yassine Riadi: Conceptualization, Methodology, Software, Validation, Formal analysis, Investigation, Resources, Data curation, Writing - original draft, Writing - review \& editing, Visualization, Supervision, Project administration, Funding acquisition. Abdellah Kaiba: Conceptualization, Software, Validation, Formal analysis, Investigation, Resources, Data curation, Writing - original draft, Visualization. El Hassane Anouar: Conceptualization, Software, Validation, Formal analysis, Investigation, Resources, Data curation, Writing - original draft, Visualization. Oussama Ouerghi: Methodology, Data curation. Elmutasim O. Ibnouf: Methodology, Data curation. Philipe Guionneau: Conceptualization, Resources, Data curation.

Acknowledgment : The author also wishes to express the gratitude to the staff of Prince Sattam Bin Abdulaziz University for providing necessary facility to carry out the research work.

Research data for this article : C $>$ Cambridge Crystallographic Data Center - Crystallographic data. Data associated with the article: CCDC 1979924: Experimental Crystal Structure Determination. 


\section{References}

1. S. Mishra. Quinazolinone and quinazoline derivatives: synthesis and biological application. Quinazolinone and Quinazoline Derivatives, IntechOpen (2019).

2. D. Wang, F. Gao. Quinazoline derivatives: synthesis and bioactivities. Chem. Cent. J., 7 (1) (2013), p. 95.

3. R. Rajput, A.P. Mishra. A review on biological activity of quinazolinones. Int. J. Pharm. Pharmaceut. Sci., 4 (2) (2012), pp. 66-70.

4. A.M. Alafeefy, A.A. Kadi, O.A. Al-Deeb, K.E. El-Tahir, N.A. Al-jaber. Synthesis, analgesic and antiinflammatory evaluation of some novel quinazoline derivatives. Eur. J. Med. Chem., 45 (11) (2010), pp. 49474952.

5. I. Ahmad. An insight into the therapeutic potential of quinazoline derivatives as anticancer agents. MedChemComm, 8 (5) (2017), pp. 871-885.

6. T.P. Selvam, A. Sivakumar, P.P. Prabhu. Design and synthesis of quinazoline carboxylates against Grampositive, Gram-negative, fungal pathogenic strains, and Mycobacterium tuberculosis. J. Pharm. BioAllied Sci., 6 (4) (2014), p. 278.

7. H.A. Abuelizz, et al. Molecular docking and anticonvulsant activity of newly synthesized quinazoline derivatives. Molecules, 22 (7) (2017), p. 1094.

8. R. Al-Salahi, E.-H. Anouar, M. Marzouk, H.A. Taie, H.A. Abuelizz. Screening and evaluation of antioxidant activity of some 1, 2, 4-triazolo [1, 5-a] quinazoline derivatives. Future Med. Chem., 10 (4) (2018), pp. 379390.

9. M.U. Rahman, A. Rathore, A.A. Siddiqui, G. Parveen, M.S. Yar. Synthesis and characterization of quinazoline derivatives: search for hybrid molecule as diuretic and antihypertensive agents. J. Enzym. Inhib. Med. Chem., 29 (5) (2014), pp. 733-743.

10. M. Saeedi, et al. Design and synthesis of novel quinazolinone-1, 2, 3-triazole hybrids as new anti-diabetic agents: in vitro $\alpha$-glucosidase inhibition, kinetic, and docking study. Bioorg. Chem., 83 (2019), pp. 161-169.

11. Y. Riadi, S. Massip, J.-M. Leger, C. Jarry, S. Lazar, G. Guillaumet. Convenient synthesis of 2, 4-disubstituted pyrido [2, 3-d] pyrimidines via regioselective palladium-catalyzed reactions. Tetrahedron, 68 (25) (2012), pp. 5018-5024.

12. M.H. Geesi, M.E. Moustapha, M.A. Bakht, Y. Riadi. Ultrasound-accelerated green synthesis of new quinolin2-thione derivatives and antimicrobial evaluation against Escherichia coli and Staphylococcus aureus. Sustainable Chemistry and Pharmacy, 15 (2020), p. 100195.

13. Y. Riadi. UV Light Mediated Palladium-Catalyzed Synthesis of 2-Substituedpyrido[2,3-D]pyrimidines. Polycyclic Aromatic Compounds (2019), pp. 1-6.

14. Y. Riadi. UV Light-mediated regioselective methylsulfanyl discrimination via Pd-catalyzed cross-coupling reactions of 2,4-dimethylsulfanylpyrido[2,3-d]pyrimidines. J. Sulfur Chem., 40 (4) (2019), pp. 351-360.

15. Y. Riadi, S. Lazar, G. Guillaumet. 'Regioselective palladium-catalyzed Suzuki-Miyaura coupling reaction of 2,4,6-trihalogenopyrido[2,3-d]pyrimidines'. Compt. Rendus Chem., 22 (4) (2019), pp. 294-298.

16. Y. Riadi, M. Geesi, O. Dehbi, M.A. Bakht, M. Alshammari, M.-C. Viaud-Massuarde. Novel animal-bone-mealsupported palladium as a green and efficient catalyst for Suzuki coupling reaction in water, under sunlight. Green Chem. Lett. Rev., 10 (2) (2017), pp. 101-106.

17. Y. Riadi, M. Geesi. Photochemical route for the synthesis of novel 2-monosubstituted pyrido [2, 3-d] pyrimidines by palladium-catalyzed cross-coupling reactions. Chem. Pap., 72 (3) (2018), pp. 697-701.

18. M.H. Geesi. Synthesis, antibacterial evaluation, Crystal Structure and Hirshfeld surface analysis of a new 2-benzylsulfanyl-3-(4-fluoro-phenyl)-6-methyl-3H-quinazolin-4-one. J. Mol. Struct. (2020), p. 127894.

19. E.H. Simpson. Prevalence of Penicillin-Resistant Streptococcus pneumoniae-Connecticut, 1992-1993. ' (1994).

20. G. Socrates. Infrared and Raman Characteristic Group Frequencies: Tables and Charts. John Wiley \& Sons (2004). 
21. A. Aminzadeh, V. Fawcett, D.A. Long. A study of some vibrational band intensities in the pre-resonance Raman spectra of naphthalene, phenazine, pyrazine, cinnoline and quinazoline. J. Raman Spectrosc., 9 (4) (1980), pp. 219-223.

22. A. Altomare, et al. SIR97: a new tool for crystal structure determination and refinement. J. Appl. Crystallogr., 32 (1) (1999), pp. 115-119.

23. G.M. Sheldrick. A short history of SHELX. Acta Crystallogr. A: Foundations of Crystallography, 64 (1) (2008), pp. 112-122.

24. L.J. Farrugia. WinGX suite for small-molecule single-crystal crystallography. J. Appl. Crystallogr., 32 (4) (1999), pp. 837-838.

25. S.K. Wolff, D.J. Grimwood, J.J. McKinnon, M.J. Turner, D. Jayatilaka, M.A. Spackman. CrystalExplorer 3.0. University of Western Australia, Perth (2012).

26. M.J. Frisch, et al. R. Gaussian 09, A. 02. Gaussian', Inc., Wallingford, CT (2009). 